\title{
PHOTOMETRIC MEASUREMENT OF THE REFLECTANCE FROM DROSOPHILA CUTICLES
}

\author{
by \\ CLAUS BARR and MOGENS BOHL PEDERSEN ${ }^{1}$
}

\author{
Institute of Genetics, University of Copenhagen \\ Oster Farimagsgade 2A, DK-1353 Copenhagen K \\ 'Present address: Department of Brewing Chemistry, Carlsberg Research Laboratory, \\ Gamle Carlsberg Vej 10, DK-2500 Copenhagen Valby
}

Keywords: Melanization, body colour mutants, microphotometry, microscope attachment

A microphotometer for measuring the reflectance of insect cuticles is described. The reflected light from a cuticle area of $0.030 \mathrm{~mm}^{2}$ is projected through the objective ocular of a stereomicroscope onto a photodiode. The photocurrent is converted to voltage and measured by a voltmeter. The method allows to distinguish objectively different shades of cuticle colour in wild type and mutant Drosophila.

\section{INTRODUCTION}

Several mutant genes in Drosophila melanogaster change the colour of the cuticle. Thus the mutants black and ebony have an increased melanization due to a deficiency of $\beta$ alanine in the cuticle. Interesting interactions occur between the black mutant gene and genes influencing the biosynthesis and catabolism of pyrimidines (1). For a closer study of these interactions it was necessary to determine objectively the colour of the cuticle on live flies in a nondestructive manner. A microphotometer which permits the measurement of the reflected light from the cuticle was therefore constructed. Since this instrument might be generally useful in the study of tanning and melanization in insect cuticles a brief description is given here.

\section{DESCRIPTION OF THE MICROPHOTOMETER}

The best area to determine the colour of the cuticle from an adult fly is the relatively flat area of the mesothorax to which no major hairs are attached (Figure 1). The area selected measures $0.030 \mathrm{~mm}^{2}$ and is projected through the objective and ocular of a Wild Heerbrugg M8 stereomicroscope onto a photodiode placed in a tubus above the ocular (Figure 2). The current produced in the photodiode by the light reflected from the cuticle is converted into voltage, amplified and measured by a millivoltmeter.

An anesthetized fly is placed on the stage of the stereomicroscope and illuminated from above by a fibrelight guide placed in a loop around the microscope objective. As light source an Intralux 


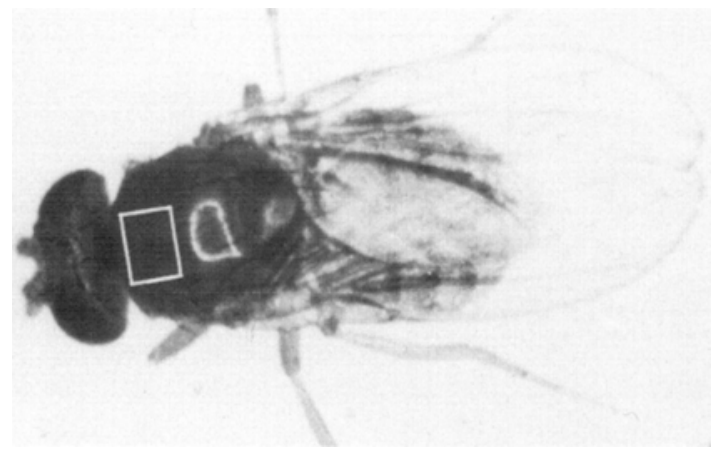

Figure 1. Female of Drosophila melanogaster seen in the mirror for positioning of the cuticle area (outlined) to be measured photometrically.

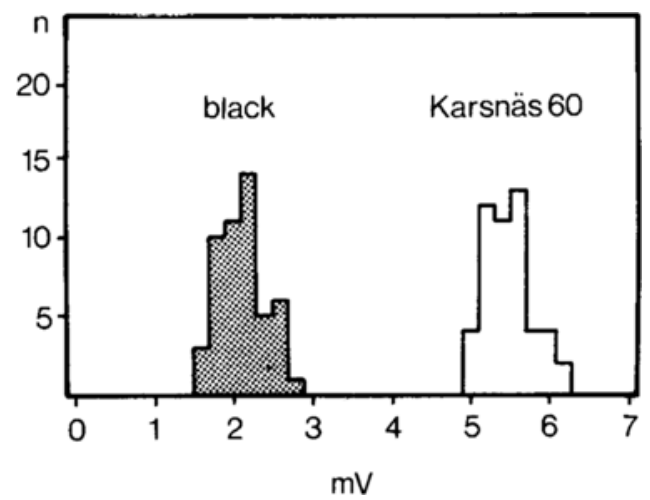

Figure 3. Histograms of reflectance measurements in $\mathrm{mV}$ for 50 Karsnäs 60 wild type Drosophila and 50 black mutant flies.
$150 \mathrm{H}$ Volpi lamp with a Volpi yellow standard filter is used. (Volpi, Switzerland). The tubus containing the photodiode (Figure 2) fits onto the side-arm of the camera adaptor Wild, type 376788 , of the stereomicroscope after insertion of a $15 \times$ Nikon CFW ocular. The cuticle area selected is projected onto the photodiode mounted on a ground glass screen in the tubus at a distance of $12 \mathrm{~cm}$ from the eye-piece. This ground glass screen can be viewed in a mirror placed at a $45^{\circ}$ angle on the top of the tubus. This permits to center the desired cuticle area onto the photodiode which has an effective measuring area of $7.5 \mathrm{~mm}^{2}$. After centering of the object the tubus is closed below the mirror with a black lid. The photodiode OP 915 (Optron Inc., USA) has a sensitivity of $0.55 \mathrm{~A} / \mathrm{Watt}$ and the light generated current is converted to voltage by coupling to an LF 357 amplifier (National, USA) as shown in Figure $2 \mathrm{~L}$, using a symmetrical set-up with a high input impedance $\left(10^{12} \mathrm{ohm}\right)$. The amplification is $V_{\text {out }}=\mathrm{i} \cdot 2 \mathrm{R}$. The obtained voltage is measured on a Philips (Holland) digital multimeter PM 2517 E with a resolution of 0.1 $\mathrm{mV}$. A black velvet cloth placed over the microscope stage is used as standard and background. The velvet gives a reflectance value of $8.3 \mathrm{mV}$ which is substracted from the value measured on the thorax cuticle.
An example of the distribution of reflectance values for the mesothorax of 50 Karsnäs 60 wild type flies is presented together with the distribution for 50 flies of the mutant black in Figure 3. The reflectance values measured for the wild type range from $5.0-6.2 \mathrm{mV}$ with an average value of $5.5 \pm 0.3 \mathrm{mV}$ and those for the black mutant from $1.7-2.9 \mathrm{mV}$ with an average value of $2.2 \pm 0.3 \mathrm{mV}$. Such microphotometric determinations of cuticle reflectance have been successfully used to distinguish quantitatively different genotypes of Drosophila in the companion paper (1).

\section{ACKNOWLEDGEMENTS}

We wish to thank Professor D. von WETTSTEIN for critical reading of the manuscript, Mr. P. ERIKSEN for photographical work, Ms. N. RASMUSSEN for preparing the figures, and Ms. H. THEM Nielsen for typing the manuscript.

\section{REFERENCE}

1. Pedersen, M.B.: Characterization of an X-linked semi-dominant suppressor of black $S u(b)$ (155.5) in Drosophila melanogaster. Carlsberg Res. Commun. 47, 391-400 (1982) 


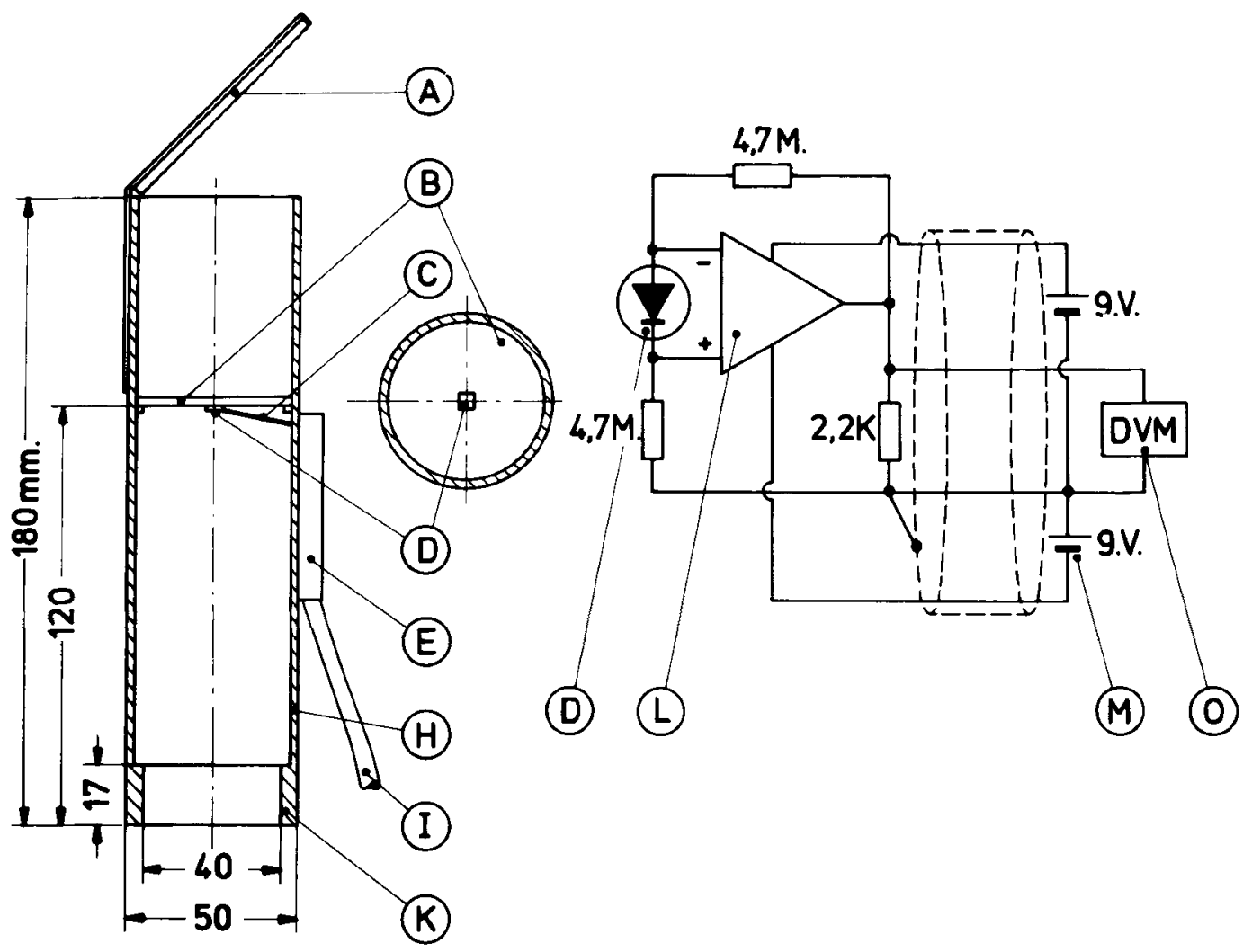

Figure 2. Diagram of the microphotometer attachment to the stereomicroscope for measurement of cuticle reflectance.

At left is shown a cross section of the camera attachment tubes with accessories. At right arrangement of the amplifier unit is depicted. $\mathrm{A}=$ mirror for viewing the fly; $\mathrm{B}=$ ground glass screen; $\mathrm{C}=$ wire connecting photodiode with amplifier, $\mathrm{D}=$ photodiode $\mathrm{OP} 915 ; \mathrm{E}=$ amplifier; $\mathrm{H}=$ tubus; $\mathrm{I}=$ cable connecting photodiode with battery and voltmeter $\mathbf{K}=$ fitting to place the attachment on the camera adaptor tubus type 376788 of the Wild stereo microscope $\mathrm{M} 8 ; \mathrm{L}=$ Operational amplifier $\mathrm{LF} 357 ; \mathrm{M}=\mathrm{GV}$ battery; $\mathrm{O}=$ Digital voltmeter with $0.1 \mathrm{mV}$ resolution. 